American Academy of Sciences. Instructions in his will established from the residue of his estate the "Rumford Professor of the Physical and Mathematical Sciences as applied to the useful Arts"' at Harvard. These eponymous memorials furthered his imprint on the scientific community. Perhaps Rumford was not unique, for adventurers of all sorts abounded in revolutionary times. Moreover, the history of technology provides us with occasional examples of scoundrels - but Rumford must be unique in the degree of his rascality. He appears to have been a man devoid of real allegiances, clever enough to exploit the political turmoil and the scientific conceptual turbulence of his times for his own good.

Sanborn C. Brown, Emeritus Professor of Physics at MIT, presents the fruits of nearly 40 years of search for the original documents relating to Rumford's career. For these efforts every subsequent scholar will be grateful. In 1962 Brown wrote Count Rumford Physicist Extraordinary, one of the publications in the Science Study Series, which related in a chronological way what he had learned of Rumford's life. Brown's new biography expands upon that earlier book without deviating from its patiently explanatory tone and linear structure.

Brown, of course, has not been alone in paying attention to Rumford's life and accomplishments. Many historians of science, historians of technology and sociologists of science have examined portions of Rumford's activities, and it is to the neglect of this informing and analytical literature that Brown's biography owes its greatest weakness. Examples are not difficult to come by. Robert Fox in The Caloric Theory of Gases (Oxford University Press, 1971) has examined Rumford's work on the nature of heat, and placed Rumford's ideas within their contemporary milieu. Although Brown cited Fox's work, he did not use it to inform his own discussion. Morris Berman has analysed the early days of the Royal Institution in Social Change and Scientific Organization: The Royal Institution, 1799 -1844 (Cornell University Press, 1978). While Berman's general interpretation and analysis is the subject of considerable debate, much of what he has said is both useful and informative to the biography of Rumford. Brown appears to have been unaware of Berman's contributions.

Reading the biography of any practising scientist (even a part-time scientist, as Rumford assuredly was) raises the question: what is the most important aspect of such biography? To be sure, the biographer owes his subject as accurate a chronicle of the chief events in the life as can be achieved. Brown has provided that for Rumford. But the biographer of a scientist also owes his reader the benefits of his analysis of the subject's endeavours, of his achievements as seen by his contemporaries, of his failures as judged by his contemporaries, and an assessment of where the subject fits into the histories of science and of technology. While Brown discusses Rumford's work on the nature of heat chronologically, he has not truly shown what motivated Thompson's extensive experiments. What is missing is the deep analysis which a historical study requires. When Brown discusses Thompson's social reforms he chronicles the major efforts, but he fails to show whether Thompson regarded his projects as intellectual solutions to complicated puzzles, as palliatives to grievous human needs or as a means for currying personal favour for himself. Above all, Brown does not appear to have realized how much of an outsider Count Rumford was; the narrative suggests that Rumford functioned at his best only when he enjoyed a perverse, self-engendered alienation. Perhaps, in this instance, the abiding question should have been "What made Rumford run?'”.

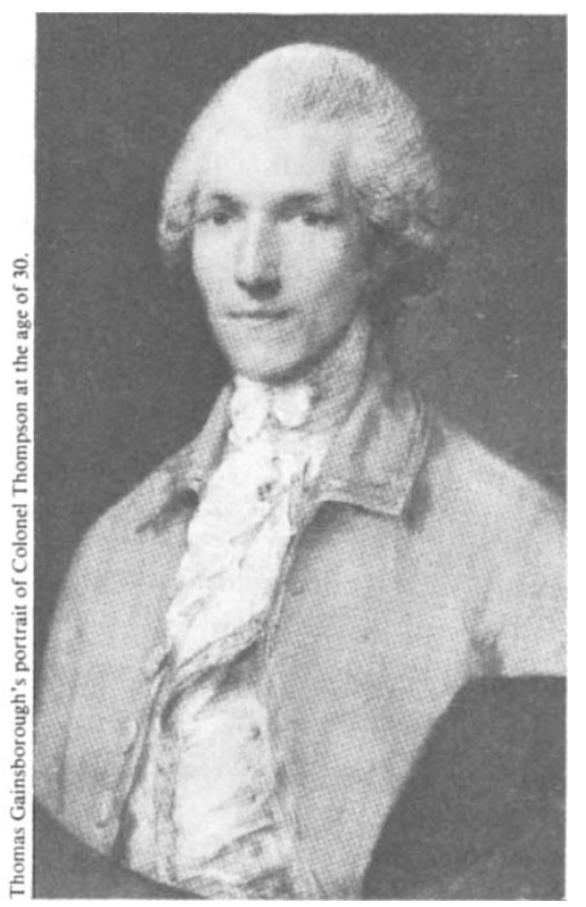

Physicists publishing research findings must do more than offer raw data. Generally, that data has to be placed within a larger conceptual framework. The historian and the biographer have the same obligation. To view a man as a twodimensional cardboard cut-out (no matter how colourful), jerked into spasmodic action by unseen wires and strings against a flat backdrop, impoverishes our understanding of him. It is on this score that Brown's biography of Rumford is most disappointing. Brown's biography is not the definitive life of Rumford, but it does offer a brave factual beginning on which subsequent analysis must rely.

Mrs. Fullmer is Professor of the History of Science at Ohio State University, Columbus, Ohio.

\section{Of special concern}

\section{Austen Albu}

Science and Technology: A Five-Year Outlook. By the National Academy of Sciences. Pp.544. (Freeman: San Francisco and Oxford, 1980.) Hardback £8.90; paperback $£ 5.40$.

IN 1977 the United States Congress legislated for a periodical Five-Year Outlook on Science and Technology. The responsibility for this work was eventually transferred to the National Science Foundation. In 1978 the Foundation asked the National Academy of Sciences to prepare a report describing the current state of significant research areas and pointing out those areas which would be of special concern within the five year period. A review procedure by members of a number of other bodies was established. Those involved included 50 contributors, 20 editorial consultants, and 170 reviewers and additional contributors. Although the resulting report is by no means comprehensive and only intended as a preliminary study, it covers a number of fields in encyclopaedic fashion and one can only express admiring astonishment that it should have been produced by March 1979.

British Members of Parliament have long envied the resources available to their American colleagues and, for all their growing interest in science and technology during the past few years, they would never have succeeded in commissioning a report on this scale. Written in a straightforward style, not over-popularized, it offers descriptions of recent and likely future developments in such fields as geology, biology and biochemistry, physics, computers, energy, and US demography and health. Some of the subjects are politically sensitive and tend to be dealt with in a rather didactic manner; but on the whole the problems requiring research in the near future seem to have been set out fairly. Of course neither the average congressman nor this reviewer is capable of judging the scientific quality of these descriptions and proposals, and the problem of choice of priorities remains as difficult as ever. I am reminded of a remark of my son's when, in his twenties, he was facing a choice in his life on which he had consulted his liberal parents: "Just like my parents, tell me all the pros and cons and leave the decision to me".

Two criticisms can be made of this report: there are no price tags attached to any proposals for the future, without which serious consideration of alternatives by a legislative body is impossible. Perhaps equally serious is the lack of any reference to Defence $R \& D$, the cost of which overshadows all the rest and which itself 
contributes indirectly to so many other fields.

The problems now facing American scientists and engineers, though vastly greater in scale, are common in advanced industrial countries. There has been a collapse of the academic boom of the 50s and $60 \mathrm{~s}$. Average annual growth at constant prices of funding for academic R\&D from 1953 to 1960 was $12 \%$; from 1960 to $1964,14 \%$; from 1968 to 1974 , zero; and from 1974 to 1978 , about $4 \%$. Despite increased numbers of graduate students, doctorates in science and engineering are declining. Total support for basic academic research declined by $8 \%$ between 1968 and 1976 and federal support by $10 \%$.

Naturally the overwhelming number of developments reported are concerned with practical and, in some cases, urgent problems: energy, material resources and health. Their solution is difficult enough in scientific terms but is increasingly hindered by social and political considerations. These are not only panic reactions as in the case of genetic manipulation or nuclear energy after Harrisburg but arise out of growing concern with environmental questions, leading to regulatory procedures. No doubt there is some special pleading here. Even the possibility of expanding the use of coal is hindered by the opposition of agrarian states to its mining in their territories and by fear of the atmospheric effects of its use in power stations. For this reason conservation is priority number one in the energy field. Of course vested interests are involved and indications of these can be detected in some of the reports. Political decisions can also distort the allocation of $R \& D$ resources, tactfully referred to in an account of the examination by "a new leadership" of the "enormous effort" of Nixon's "War on Cancer" in order to achieve a more balanced programme.

Many readers of this fascinating book must be left with two impressions: the enormous area remaining for scientific R\&D to deal with the world's material problems and search for knowledge; and, in a divided world, the considerable international cooperation here reported and the need and scope for its further enlargement.

Austen Albu was a Member of Parliament from 1948 to 1974, and a Visiting Research Fellow of the University of Sussex Science Policy Unit, Brighton, UK, from 1975 to 1979.

\section{Bringing Man poetically to life}

\section{Yves Coppens}

The People of the Lake: Man, His Origins, Nature and Future. By Richard E. Leakey and Roger Lewin. Pp.223. (Collins: London; Doubleday: New York, 1979.) $£ 6.50$.

People of the Lake is a kind of essay on Man. Pleasantly readable, it puts forward in a little over 200 pages an overall view of our species in both a historical and comparative context which is thoroughly satisfying for anyone with a naturalist's turn of mind. Although the reader may regret a certain lack of rigour in the comparative approach, as too great an emphasis is placed on seeking out good examples to back up the argument at the expense of a critical attitude towards similarities and differences, the attempt is nevertheless an extremely interesting one, and one worthy of being encouraged.

Divided into 11 chapters, the book is in fact made up of two sections of almost equal length; the first of these, comprising the first five chapters and part of the eleventh, is devoted to palaeontology, the origin and evolution of Man, from the first primates of $70 \mathrm{Myr}$ ago to Homo sapiens sapiens; the second (Chapters 6, 7, 8, 9, 10 and the remainder of Chapter 11) concerns itself with ethology, human behaviour and the search within the animal kingdom for Man's origins and the direction of his evolution. Given the training and special interests of the authors, this second part is more an essay in prehistoric ethology: just like chimpanzees, gorillas, baboons or geladas, contemporary Man is used in an attempt to reconstruct the lifestyle, psychology and behaviour of ancient Man. In spite of what might be inferred from the sub-title, neither the future of mankind, nor even his present condition, seem to be the writers' principal concern.

The point of departure - hence the title - is the palaeontological research carried out by Richard Leakey over the past 12 years on the shores of Lake Turkana in Kenya. In 1967, Richard Leakey, together with Francis Clark Howell and myself and initially Louis Leakey, his father, and Camille Arambourg - played a part in setting up the important international expedition along the Omo River in Ethiopia, to the north of Lake Turkana itself; and it was during one of the many flights that had to be made back and forth between Nairobi and his camp on the Omo that he noticed the sedimentary formations outcropping on the eastern banks of the lake. He decided there and then to investigate, and since 1968 a dozen or so separate expeditions have provided an extraordinary collection of human fossils, their age ranging from more than $4 \mathrm{Myr}$ to less than $1 \mathrm{Myr}$ and including half a dozen skulls in an excellent state of preservation, highlighted by the famous ER-KNM 406 (Australopithecus boiset), 1470 (Homo habilis) and 3733 (Homo erectus). These expeditions, known as the Koobi Fora Project, make up one of the four largescale international projects under way in the Rift Valley of East Africa and concerned with the problems surrounding the origin of Man. The other three are the Olduvai expedition (more recently Olduvai-Laetoli), originating with Louis Leakey as long ago as 1931 and under the direction initially of Louis Leakey, then of Louis and Mary Leakey and, since Louis' death in 1972, of Mary Leakey alone; the international Omo expedition for which Francis Clark Howell and myself were responsible over eight further seasons after the departure of Richard Leakey in 1968; and the Afar international expedition, which began work in 1972 and has since been under the supervision of Maurice
Taieb, Donald Johanson and myself. The People of the Lake themselves, of course, are these fossil men of about $2 \mathrm{Myr}$ ago (Australopithecus boisei and Homo habilis), whom the authors bring poetically to life again as early as the first chapter of the book, in a reconstructed landscape on the banks of a palaeolithic Lake Turkana.

The palaeontological résumé provided is rather conventional but not without interest. It traces the links between Cretaceous and Quaternary forms, the change from a nocturnal to diurnal life (and the consequent improvement in eyesight), and, much nearer in time to ourselves, the straightening up of the body and its probable successive implications the freeing of the hands, work, development of the sweat glands, loss of hair and the appearance of a protective pigmentation for the body. Considerable passages of the book are devoted to this possible ancestor of Man, the quadruped Ramapithecus, and his erect descendant the Australopithecus, and to the irritating gap of 4 Myr that separates them.

The ethological aspects examined in the second section of the book represent in many cases interesting approaches to problems which are not usually dealt with in the context of prehistory. They all arrive at the same fundamental conclusion: that Man is as he is because at the time of his origin he shared his food with the other people in his group - the development of his intelligence (and of his language, which is no more than a manifestation of his intelligence), the extraordinary transformation of his technology, his inclination for reciprocal altruism and for family life, even his obsession with sex - are the fruits of his cooperative life and of his mixed economy based on the male's hunting and the female's gathering: everyone is in part dependent on others. With this idea established as their foundation, the authors go on to debate a wide range of problems raised, rightly or wrongly, by our times, or by other writers whose success has 